Geopolítica(s) Revista de estudios sobre espacio y poder ISSN: 2172-3958

\title{
Radiografía democrática del extractivismo minero en América Latina ${ }^{1}$
}

\author{
Manuel Ignacio Martínez Espinoza²
}

Recibido: 11 de enero de 2017 / Aceptado: 30 de noviembre de 2017

Resumen. El presente artículo analiza el extractivismo minero en América Latina haciendo dos aportaciones principales. Primero, planteando un modelo explicativo del extractivismo minero en América Latina basado en cuatro pautas multitemáticas, imbricadas y compartidas en la región: la irrupción de la minería transnacional, la asistencia institucional, la apropiación territorial y la conflictividad persistente. El segundo aporte del artículo es la interpelación del modelo del extractivismo minero con una lectura plural y antagonista de la democracia, misma que cuestiona la faceta liberal-representativaprocedimental que ha sustentado al extractivismo minero y ha relegado a quienes se han opuesto al mismo. Se concluye que, a pesar de las excepciones al modelo, el extractivismo minero perpetúa la base económica primario exportadora, la dependencia externa y la colonialidad en América Latina pero que sus límites se hallan precisamente donde comienza el poder constituyente de la democracia.

Palabras clave: extractivismo minero; democracia; América Latina; desarrollo; movimientos sociales.

\section{[en] Democratic In-Depth Analysis of Mining Extractivism in Latin America}

Abstract. The article analyses mining extractivism in Latin America. It makes two major contributions.
First, it sets forth an explicative model of mining extractivism in Latin America based on four cross-
regional patterns: the emergence of transnational mining, institutional assistance, land-grabbing and
constant unrest. Secondly, the article discusses the model of mining extractivism drawing on a plural
and antagonist reading of democracy. The latter is critical with the liberal-representative-procedural
dimension of mining extractivism and has paid little attention to opponents to the model. The article
concludes that, in spite of the exceptions to the model, mining extractivism perpetuates Latin America's

1 El presente artículo es el resultado de una investigación posdoctoral sobre la minería y los pueblos indígenas en Chiapas y Guatemala iniciada en el 2011. En el informe final de esa investigación, presentado en el 2013, se destacó la existencia de profundas similitudes en ambos casos que se repetían en otros países según se pudo constatar en diferentes informes y estudios. Se decidió, entonces, investigar en el resto de los países latinoamericanos los paralelismos hallados previamente. Para asegurar la validez del método comparativo se siguió el lineamiento central de la igualdad de criterios, de manera que se investigaron 17 países latinoamericanos (Argentina, Bolivia, Brasil, Chile, Colombia, Costa Rica, Ecuador, El Salvador, Guatemala, Honduras, México, Nicaragua, Panamá, Paraguay, Perú, Uruguay, Venezuela) en el mismo periodo (1990-2017) y empleando el mismo tipo de fuentes para todos los casos (estadísticas de organismos oficiales, estudios académicos e informes de organizaciones civiles y de derechos humanos). El presente texto presenta una sistematización de los hallazgos de la investigación articulados en las pautas identificadas y bajo un análisis de la democracia desde el enfoque crítico del posfundacionalismo.

2 Consejo Nacional de Ciencia y Tecnología. Comisionado al Centro de Estudios Superiores de México y Centroamérica de la Universidad de Ciencias y Artes de Chiapas.

E-mail: manuel.martinez.espinoza@gmail.com 
primary-sector and export-oriented economic basis, her external dependence and coloniality, while nonetheless shows that democracy's constituent power sets up limits to this mining model.

Keywords: mining extractivism; democracy; Latin America; development; social movements.

\section{[pt] Radiografia democrática do extrativismo mineiro em América Latina}

Resumo. Este artigo analisa o extrativismo mineiro na América Latina, fazendo duas contribuições principais. Em primeiro lugar, apresentando um modelo explicativo do extrativismo mineiro na América Latina com base em quatro diretrizes multitemáticas, imbricados e partilhados na região: o surgimento da mineração transnacional, o cuidado institucional, a apropriação da terra e os conflitos persistentes. A segunda contribuição do artigo é o questionamento do modelo de mineração com uma leitura plural e antagonista da democracia, mesma que questiona a faceta liberal-representativaprocessual que tenha sofrido o extrativismo mineiro e relegado aos que se opõem a isso. Conclui-se que, apesar das exceções ao modelo, o extrativismo mineiro perpetua a base econômica primárioexportadora, a dependência externa e a colonialidade na América Latina, mas os seus limites são precisamente onde o poder constituinte da democracia começa.

Palavras-chave: extractivismo mineiro; democracia; América Latina; desenvolvimento; movimentos sociais.

Sumario. Introducción. 1. El extractivismo minero en América Latina. 1.1. Primera pauta: La irrupción de la minería transnacional. 1.2. Segunda pauta: La asistencia institucional. 1.3. Tercera pauta: La apropiación territorial. 1.4. Cuarta pauta: La conflictividad persistente. 2. Democracia contingente, extractivismo minero interpelado. Conclusiones: excepciones, persistencias y desafíos. Bibliografía.

Cómo citar: Martínez Espinoza, Manuel Ignacio (2018) "Radiografía democrática del extractivismo minero en América Latina". Geopolítica(s). Revista de estudios sobre espacio y poder, vol. 9, núm. 1, $35-62$.

Los conflictos epistemológicos son siempre, inseparablemente, conflictos políticos

Pierre Bourdieu

\section{Introducción}

El presente artículo analiza el extractivismo minero en América Latina desde el prisma de la democracia. Específicamente, este escrito plantea tres nodos argumentativos. En primer lugar, el reconocimiento del extractivismo minero como un fenómeno multipolar que resulta imperioso examinar rigurosa, exhaustiva y críticamente desde la academia. En segundo lugar, la tesis de que, aún con sus diferencias, es posible distinguir pautas que configuran un modelo del extractivismo minero en América Latina. Por último, la interpelación de ese extractivismo minero con una lectura plural, antagonista y contingente de la democracia.

A pesar de la abundancia de libros, artículos y reportes, en el estado de la cuestión sobre el tema no existe un estudio como éste. Es decir, un análisis interdisciplinario que plantee directrices regionales comparadas, sustentadas en datos actualizados y que interprete al extractivismo minero con el tamiz de la tensión incesante entre el poder constituido y el poder constituyente, propio de la democracia. He aquí el aporte del presente artículo. 
La estructura expositiva se integra de tres apartados. El primero de ellos presenta el modelo del extractivismo minero en América Latina basado en ámbitos, intereses, actores, procesos e impactos correlacionados en la región. En el segundo apartado se escudriña el extractivismo minero desde la democracia articulada como una categoría analítica tanto instituida como por instituir, es decir, disputada. Por último, el tercer acápite corresponde a las conclusiones, donde se analizan tanto las excepciones como el núcleo económico del modelo extractivista y se cierra con una reflexión final sobre la democracia y el extractivismo minero en América Latina.

\section{El extractivismo minero ${ }^{3}$ en América Latina}

Un vector no puede analizarse como si tuviese una trayectoria independiente, porque su itinerario es producto de su interacción con distintos factores

Immanuel Wallerstein

A pesar de que la diversidad y la complejidad son sus sellos distintivos, los hallazgos de investigación permiten afirmar que en América Latina impera un modelo del extractivismo minero que se ha configurado con cuatro paralelismos imbricados y compartidos en la absoluta mayoría de los países latinoamericanos. Estos patrones se refieren a la incursión, el respaldo, la ejecución y los efectos de la minería transnacional. Dichas correlaciones se analizan en este apartado.

\subsection{Primera pauta: La irrupción de la minería transnacional}

El primer basamento del modelo extractivista minero corresponde al surgimiento e incursión de la minería transnacional en América Latina. Este proceso se asentó a principios del 2000 con el incremento de los precios internacionales de las materias primas, demandadas por los países centrales y las potencias emergentes (Svampa, 2012). Por ejemplo, los precios del oro y la plata se dispararon en un $750 \%$ en el periodo 2000-2012 (Howard, 2012). Ante tal escenario, los metales y los minerales se reconfiguraron en activos financieros para plegarse como una esfera de inversión, lo que se ha catalogado como Commodities.

Dadas sus profusas vetas minerales ${ }^{4}$, América Latina se convirtió en un destino idóneo para la extracción minera, de manera que el número de toneladas de metales

3 Siguiendo a Eduardo Gudynas, en este texto se entiende al extractivismo como "un tipo de extracción de recursos naturales, en gran volumen o alta intensidad, y que están orientados esencialmente a ser exportados como materias primas sin procesar, o con un procesamiento mínimo" (Gudynas, 2013: 3). El extractivismo contempla los ámbitos de los hidrocarburos, los agronegocios, los biocombustibles y la minería. Aunque existen autores que utilizan el término de "neoextractivismo" para subrayar su intensidad contemporánea, en este texto se emplea el de "extractivismo" para resaltar el carácter histórico-estructural que se mantiene en la región pues, como afirma Eduardo Galeano, "La historia de América Latina es la historia del despojo de los recursos naturales". Aun así, hay estudiosos que ven similitudes entre el extractivismo con la acumulación originaria de Karl Marx: "Con todo, si seguimos el análisis que Marx (1975 [1894]) ofrece sobre la acumulación originaria de capital - la cual pondera el florecimiento de las manufacturas laneras y la consiguiente alza de precios como acicate para los abusos y el despojo-, encontraremos que la situación descrita por el autor es muy similar al actual neoextractivismo" (Villafuerte, 2014: 123).

4 “América Latina cuenta con inmensos activos de recursos naturales no renovables: posee un 13\% de las reservas de petróleo del planeta, $65 \%$ del litio, $49 \%$ de la plata, $44 \%$ del cobre, 33\% del estaño, 32\% del molibdeno, 26\% 
extraídos en la región aumentó cuatro veces en el periodo 1978-2008 (West \& Schandl, 2013), llegando a erigirse en la zona que recibe los mayores flujos de inversión minera en el mundo (OCMAL, 2015: 5). El capital minero transnacional proviene principalmente de Canadá, China, Estados Unidos, Japón, Corea del Sur, Australia, Inglaterra y Sudáfrica (Hernández Morales, 2014: 50-51).

\section{Cuadro 1. Territorio concesionado para actividades mineras en América Latina}

\begin{tabular}{|l|c|c|c|}
\hline \multicolumn{1}{|c|}{ País } & $\begin{array}{c}\text { Total de hectáreas } \\
\text { concesionadas a la mineria }\end{array}$ & $\begin{array}{c}\text { Porcentaje de territorio } \\
\text { concesionado a la minería }\end{array}$ & $\begin{array}{c}\text { Fecha del } \\
\text { dato }\end{array}$ \\
\hline Argentina & $18.300 .000 \mathrm{ha}^{5}$ & $6,55 \%$ & 2016 \\
\hline Bolivia & $2.285 .583 \mathrm{ha}^{6}$ & $2,08 \%$ & 2013 \\
\hline Chile & $31.183 .231 \mathrm{ha}^{7}$ & $41,00 \%$ & 2013 \\
\hline Colombia & $5.292 .165 \mathrm{ha}^{8}$ & $4,63 \%$ & 2012 \\
\hline Ecuador & $772.729 \mathrm{ha}^{9}$ & $2,87 \%$ & 2016 \\
\hline Guatemala & $527.984 \mathrm{ha}^{10}$ & $4,85 \%$ & 2017 \\
\hline Honduras & $184.754 \mathrm{ha}^{11}$ & $1,64 \%$ & 2017 \\
\hline México & $22.100 .000 \mathrm{ha}^{12}$ & $11,30 \%$ & 2017 \\
\hline Nicaragua & $1.194 .909 \mathrm{ha}^{13}$ & $9,17 \%$ & 2015 \\
\hline Perú & $18.830 .090 \mathrm{ha}^{14}$ & $14,65 \%$ & 2017 \\
\hline
\end{tabular}

Fuente: Elaboración propia con base en las fuentes citadas para cada país.

de la bauxita, $23 \%$ del níquel, $22 \%$ del hierro y $22 \%$ del zinc. De acuerdo con las tendencias marcadas por la década 2000-2010, 13 países de la región están entre los 15 mayores productores de materias primas minerales del mundo" (RRI, 2013: 40).

5 Fuente: Ministerio de Energía y Minería. Presidencia de la Nación (2016) Minería Argentina: lo mejor está por venir, p. 12. Disponible en URL:<http://pdac2016.minem.gob.ar/presentacion-argentina-pdac-2016-es.pdf $>$. [Consultado el 14-06-16].

6 Fuente: Servicio Geológico Minero. Estado Plurinacional de Bolivia. "Contratos y solicitudes de arrendamiento minero existentes en el territorio nacional-gestión 2013". Disponible en URL: $<$ http://sergeomin.gob.bo/images/memoria2013/cartografia.html>. [Consultado el 30-06-16].

7 Fuente: Ministerio de Minería. Gobierno de Chile. Disponible en URL: $<\mathrm{http}: / /$ www.sernageomin.cl/pdf/mineria/estadisticas/estadisticas $\% 20 \mathrm{de} \% 20$ concesiones $\% 20 \mathrm{mineras} /$ propieda d minera 2 2013.pdf>. [Consultado el 01-07-16].

8 Fuente: Ministerio de Energía y Minas (2014) Anuario Estadístico Minero Colombiano 2007-2012, p. 82. Disponible en URL: <https://www.minminas.gov.co/anuario-estadistico-minero $>$. [Consultado el 14-06-16].

9 Fuente: Agencia de Regulación y Control Minero. Gobierno Nacional de la República del Ecuador. Disponible en URL: <http://www.controlminero.gob.ec/>. [Consultado el 04-10-17].

10 Fuente: Ministerio de Energía y Minas. Gobierno de la República de Guatemala. "Derechos mineros otorgados por departamento". Disponible en URL: <http://www.mem.gob.gt/mineria/catastro-minero/derechos-minerosotorgados-por-depto/>. [Consultado el 04-10-17].

11 Fuente: Instituto Hondureño de Geología y Minas (INHGEOMIN). Unidad registro minero y catastral (2017) "Listado de concesiones otorgadas al 30 de junio del 2017". Disponible en URL: $<$ http://portalunico.iaip.gob.hn/portal/index.php?portal=342>. [Consultado el 05-10-17].

12 Fuente: Gobierno de los Estados Unidos Mexicanos. Presidencia de la República (2017) "5to Informe de Gobierno 2016-2017”. Ciudad de México, agosto de 2017, p. 505. Disponible en URL: $<$ http://www.presidencia.gob.mx/quintoinforme/>. [Consultado el 05-10-17].

13 Fuente: Ministerio de Energía y Minas. Dirección General de Minas. Dirección de administración y control de concesiones (2017) "Estadísticas catastrales mineras", p. 1. Disponible en URL: <www.mem.gob.ni/wpcontent/uploads/2017/09/ESTADISTICAS-CATASTRALES-MINERAS-020817.pdf>. [Consultado el 05-1017].

14 Fuente: Ministerio de Energía y Minas. Instituto Geológico, Minero y Metalúrgico. Gobierno de Perú (2016) "Ubicación de los derechos mineros por Departamento a nivel nacional". Disponible en URL: $<$ http://ecatastro.ingemmet.gob.pe:83/PresentacionDatos/ReporteDMDpto.aspx $>$. [Consultado el 15-06-16]. 
Un indicador relevante de la irrupción minera son las concesiones, esto es, los derechos que los gobiernos otorgan para la exploración y/o explotación de minera. Como puede intuirse, a partir del año 2000 se registró un incremento del número de concesiones mineras en los países latinoamericanos. Por citar dos casos, en Brasil las concesiones mineras pasaron de 142 en 1999 a 404 en el 2009, es decir, un aumento de casi 300\% en un periodo de 10 años (MME, 2011: 25). En Guatemala existían 27 licencias mineras en el año 2000, cifra que se acrecentó a 116 en enero del 2012; es decir, en poco más de 11 años hubo un incremento en torno al $430 \%$ (Villafuerte, 2014: 113-114). Se ha aprobado un número tan descomunal de concesiones mineras que un informe de Greenpeace señaló que, "incluso si hubiese personal y presupuestos adecuados disponibles, los reguladores no tendrían la capacidad de supervisar responsablemente tantos proyectos" (Morán, 2013: 4).

Por lo anterior, en América Latina se han ido trazando paisajes donde gran parte de las tierras están destinadas para las actividades mineras. Como se constata en el Cuadro 1, las últimas cifras oficiales recopiladas delatan que un número cuantioso de superficie territorial está concesionada a la minería. Las cifras indican una presencia significativa de la minería en América Latina, ya sea con porcentajes de los territorios nacionales concesionados en más del $10 \%$ (como el $41 \%$ de Chile, el $14,6 \%$ de Perú y el $11,3 \%$ de México) o con porcentajes menores al $10 \%$ pero donde tales concesiones superan el millón de hectáreas (como las más de 18 millones de hectáreas en Argentina, las más de 5 millones en Colombia, las más de 2 millones en Bolivia y el más de 1 millón en Nicaragua).

El auge de la minería transnacional en América Latina también devela un factor propicio para tal crecimiento, el resguardo institucional, el cual es otro patrón en la región.

\subsection{Segunda pauta: La asistencia institucional}

La segunda pauta se refiere a las facilidades institucionales que se han otorgado a la minería transnacional en América Latina en los últimos años. Tales aquiescencias involucran los ámbitos normativos, administrativos, tributarios y discursivos.

En el ámbito normativo, 15 países de la región han promulgado nuevas legislaciones mineras o han reformado las existentes desde la década de 1990: Argentina (1993 y 1995), Brasil (1996 y 2015), Bolivia (1997 y 2014), Colombia (2014), Costa Rica (1998), Cuba (1995), Ecuador (1991 y 2008), El Salvador (2012), Guatemala (1997), Honduras (1998 y 2013), México (2014), Panamá (2011), Perú (1991), Uruguay (1991 y 2011) y Venezuela (1999 y 2010). Llama la atención los casos de Brasil, Bolivia, Ecuador, Honduras, Uruguay y Venezuela, pues reformaron su marco normativo minero en dos décadas diferentes. A grandes rasgos, esos cambios tuvieron el objetivo de otorgarles a las empresas extractivas "seguridad jurídica, garantía a la inversión y un clima de negocios atractivo" (RRI, 2013: 41); esto es, fueron modificaciones para institucionalizar la minería transnacional.

Tales facilidades pueden agruparse en dos tipos: las simplificaciones administrativas y las ventajas tributarias. Por un lado, las directrices reglamentarias se han orientado a allanar el procedimiento de adjudicación y otorgamiento de las concesiones mineras, lo que, entre otros cambios, implicó reducir los plazos y los requisitos de los estudios de impacto ambiental. Así, en Panamá se rebajó de 20 a 10 días el período para que la sociedad exprese objeciones a los estudios ambientales. 
En Bolivia se redujeron los plazos para la Declaratoria de Impacto Ambiental de 190 a 35 días en 2008. En Colombia, el Decreto de 2014 (conocido como de "licencias express") le restó 30 días al plazo para el otorgamiento de licencias ambientales; pero lo significativo es que el gobierno colombiano primero adjudica la concesión minera y luego otorga la licencia ambiental. En Chile, Guatemala y Perú también se otorgan primero las concesiones mineras y después se aprueban los Estudios de Impacto Ambiental (OCMAL, 2012: 124).

Por el lado de las ventajas tributarias, éstas se refieren a incentivos fiscales a las inversiones extractivas para incrementar las tasas de ganancia. Por ello, las regalías que las empresas mineras pagan en Guatemala no superan el 5\% sobre el valor bruto del mineral. En Argentina, Brasil y Nicaragua las regalías no superan el 3\%. En Panamá las regalías se cobran sobre el $2 \%$ de la producción bruta. En México, las empresas mineras pagaron tan sólo el 1\% de derechos en relación con su producción en el 2014, cantidad que, aun siendo baja, es superior al $0.4 \%$ que dichas empresas pagaron al país en el $2006^{15}$. Además, existen otros atajos fiscales, como los contratos de estabilidad tributaria para mantener los impuestos aplicables al momento de la adjudicación de la concesión minera, los cuales se han firmado en Chile, Ecuador y Perú.

Por si fuera poco, el apoyo institucional a la minería también se ha sustentado en elementos discursivos que, entroncándose en una matriz ideológica hegemónica sobre el desarrollo, esgrimidos por figuras públicas y utilizando la influencia de los medios de comunicación, se han puesto al servicio del extractivismo.

Como ha sido analizado por varios autores ${ }^{16}$, el sistema discursivo del desarrollo es una metanarrativa homogeneizante y excluyente que se despliega en prácticas totalizantes que, siguiendo el estilo foucaultiano, produce regímenes de verdad que colonizan la realidad. Dado que la minería transnacional ha articulado sus estrategias argumentativas con el discurso del desarrollo para autolegitimarse (Leff, 2003), se han producido maniobras retóricas para amalgamar a la minería con campos semánticos vinculados al desarrollo, por lo que, en la retahíla de argumentos a favor de la minería afloran términos como "progreso", "crecimiento" y "sostenibilidad", construyéndose así "ideas fuerza" que afianzan la retórica legitimatoria, favoreciendo que se presente sin tapujos a la minería como económica, ambiental y socialmente responsable (Antonelli, 2009: 42). Inclusive, tales marcos discursivos se han utilizado en países con gobiernos que se han ubicado en el espectro de la izquierda, como Argentina, Bolivia, Chile, Ecuador, Perú, Uruguay y Venezuela, por lo que su postura se ha catalogado como "neoextractivismo progresista" (Gudynas, $2009)^{17}$.

Los apoyos institucionales de los Estados latinoamericanos hacia la minería pueden explicarse, sino como incorporación, al menos sí como avenencia a la serie

15 Los datos fueron extraídos de las siguientes fuentes: para Argentina y Brasil [Ver URL: $<$ http://www.idconline.com.mx/juridico/2014/01/21/mineria-mas-gravada-que-nunca $>$. Consultado el 14-0616] para El Salvador (OCMAL, 2011); para Colombia, Guatemala y Panamá (RRI, 2013), para Nicaragua (Garay, 2014) y para México (Saúl, 2015).

16 Debido a su profusión y suficiencia analítica, se recomienda revisar las siguientes fuentes bibliográficas sobre el discurso del desarrollo: Álvarez Leguizamón (2008), Escobar (1998), Leff (2008), Rist (2004) o Sachs (1999).

17 Para conocer análisis pormenorizados y críticos sobre la promoción del extractivismo por parte de gobiernos progresistas en Sudamérica, se recomienda revisar las siguientes fuentes: Gudynas (2009), Gudynas (2011), OCMAL (2015), Svampa (2008) o Villegas (2014). 
de alineaciones y acuerdos a favor de ese sector extractivo que configuraron lo que propongo denominar como un "Régimen Internacional Minero". Esto es, los consensos, reglas y estrategias en torno a la minería que establecieron los actores con capacidad de decisión en la arena internacional, delimitando así los comportamientos admisibles y/o válidos para el resto de los actores. Especialmente, debe considerarse al Banco Mundial pues fue el organismo internacional que, como se ha documentado ${ }^{18}$, impulsó reformas legales (Bridge, 2004) y tributarias para fomentar la inversión minera en América Latina, para lo cual ofreció asistencia técnica y otorgó préstamos a Perú, Ecuador y Bolivia en 1991, a México en 1992, a Argentina en 1993, a Brasil en 1996, a Guatemala y El Salvador en 1997, y a Honduras en 1998 (OCMAL, 2012: 5), además de financiar proyectos a través de su subsidiaria, la Corporación Financiera Internacional.

Aunque el amparo institucional en los ámbitos normativos, administrativos, tributarios y discursivos ha influido en el apogeo de la minería transnacional en América Latina, ese auge reclama un mayor escrutinio sobre la ocupación minera de los territorios, lo que al replicarse en la región, se vuelve también en una pauta.

\subsection{Tercera pauta: La apropiación territorial}

La minería contemporánea utiliza principalmente el método de extracción conocido como de "cielo abierto" debido a que facilita la explotación intensiva de minerales, llegando a generar diariamente hasta tres veces más carga mineral que con el método subterráneo (Sariego et al., 1988: 321).

Básicamente, la minería a cielo abierto consiste en estallar el material rocoso, triturarlo, bañarlo en una mezcla de agua con cianuro y otros ácidos (proceso conocido como lixiviación) para concluir con la fundición de los metales obtenidos ${ }^{19}$. Para este proceso se requiere de enormes extensiones territoriales, por lo que la minería a gran escala ha operado en América Latina bajo lógicas de "expropiación geográfica" (Machado, 2011), es decir, con pretensiones de apropiación de los recursos naturales, generando con ello efectos perniciosos en los territorios.

En primer lugar, la minería "a cielo abierto" gasta enormes cantidades de agua pues se calcula que requiere de al menos un metro cúbico por segundo ininterrumpidamente (Machado, 2010: 78). Pero las dosis pueden ser mayores: la mina Marlin, en Guatemala, llegó a utilizar hasta 250 mil litros de agua por hora; la mina Pascua Lama, ubicada en la cordillera de los Andes, consume 1,296 mil litros de agua por hora, y la mina El Cerrejón, en Colombia, dispone de 17 millones de litros de agua al día ${ }^{20}$. Como una referencia, conviene apuntar que la cantidad de agua por hora que llegó a utilizar la mina Marlin mientras estuvo en funcionamiento equivalió a la misma proporción que consume una familia campesina durante 22 años (Castagnino, 2006: 13). Así, las minas "a cielo abierto" tienden a acabar con los recursos hídricos por más grandes que éstos sean (Hernández Morales, 2014: 62).

\footnotetext{
18 Véase CHA (2009), Hernández Morales (2014), OCMAL (2012), Svampa (2008) y Walter \& Urkidi (2015).

19 Para conocer a detalle el proceso de la minería "a cielo abierto", revísese Lamberti (2011: 304-305) y Morán (2013: 3-6).

20 Los datos fueron extraídos de las siguientes fuentes: para la mina Marlin, Castagnino (2006: 13), para la mina Pascua Lama, Morán (2013: 17), y para la mina El Cerrejón, OCMAL (2015: 50).
} 
Además, cuando no la consume totalmente, la minería contamina el agua ya que, para separar los metales de la roca, emplea elementos y metales pesados como arsénico, azufre, cianuro, mercurio y uranio, entre otros, los cuales contaminan las fuentes acuíferas y son altamente tóxicos: "Los drenajes ácidos pueden «eliminar» en esencia toda la vida acuática a lo largo de kilómetros" (Morán, 2013: 7). Por aportar un dato, en el 2013 la Dirección General de Aguas de Chile reconoció como zonas de catástrofe a ocho comunas donde existe actividad minera a gran escala (OCMAL, 2015: 42).

En relación con el suelo, éste se deteriora por los derrames y vertidos de materiales tóxicos y la sedimentación de polvo contaminado, de manera que, cuando no se remueve totalmente, el suelo pierde sus funciones básicas (Delgado et al., 2013: 192). De igual forma, la megaminería también es factor de polución para el aire al emitir material particulado, metales pesados, vapores, gases y altos niveles de ruido (RRI, 2013: 61). Por si fuera poco, se producen gases retenedores de calor en la atmósfera, por lo que la minería "a cielo abierto" contribuye sustancialmente al cambio climático (Hernández Morales, 2014: 63).

También hay repercusiones en las especies debido a la alteración y pérdida de hábitat por la remoción de la cobertura vegetal, el relleno o desvío de cuerpos de agua, la degradación de hábitats acuáticos y la liberación de contaminantes en el ambiente. Todo ello propicia el desplazamiento y hasta la desaparición de especies (RRI, 2013: 62).

Se acentúa entonces que no puede haber megaminería sin el control de grandes extensiones de suelo, bosques, cimas, recursos hídricos y biodiversidad. Ante tal hecho, las industrias extractivas mineras requieren que los Estados latinoamericanos les concedan, más allá de las concesiones mineras, la potestad de usufructuar el territorio y sus recursos naturales, lo cual suele otorgárseles bajo la nomenclatura de "declaratoria de utilidad pública" (Sánchez-Albavera \& Lardé, 2006). Pongamos por caso el de Chile, donde se entregan "concesiones plenas", es decir que los recursos naturales pasan a ser propiedad de quien obtenga la concesión minera hasta el momento en que el yacimiento se agote (OCMAL, 2015: 42).

Otro factor que incide en el territorio es que las concesiones mineras en la región suelen tener una vigencia de entre 25 y 30 años (RRI, 2013: 41). En el caso de México, la concesión se otorga por un periodo inicial de 50 años, con la posibilidad de renovarse por el mismo periodo (Hernández Morales, 2014: 103-104). En Chile y Perú las concesiones para explotación minera se otorgan por plazos indefinidos (OCMAL, 2012: 124).

La megaminería también perjudica gravemente a las sociedades locales. Por principio de cuentas, la salud de los habitantes se ve seriamente afectada, pues enfermedades respiratorias, gastrointestinales, dermatológicas, endocrinas, cardiovasculares y neurológicas suelen presentarse por los elementos que las minas dispersan en el medio ambiente (González, 2015). Además, la contaminación, la degradación y la expropiación de los recursos naturales impactan negativamente en la producción y calidad de los alimentos obtenidos por vía agraria, ganadera, marina o forestal, de manera que también se vulnera la soberanía alimentaria.

Además, las minas a cielo abierto perturban otros ámbitos de las poblaciones locales pues las dinámicas locales se reorientan al servicio de la mina. Por consiguiente, se entablan acciones para respaldar tal objetivo, no importando su legitimidad o su legalidad. La adquisición malversada de terrenos, el surgimiento de 
grupos armados paraestatales, la aparición de economías paralelas como el microtráfico y la prostitución, son algunas de ellas. De esta forma, la pérdida de formas tradicionales de subsistencia, el debilitamiento del tejido social y el desplazamiento forzado de poblaciones son afectaciones comunes en las localidades donde se ha asentado un proyecto minero a gran escala (RRI, 2013: 12).

Entonces, la megaminería opera destruyendo la coherencia local de los territorios, desarticulando los flujos socio-productivos endolocales y rearticulándolos como fragmentos subordinados a procesos productivos globales. Se trata de la uniformización de los territorios mineros para crear nuevos enclaves de exportación (Svampa, 2008: 19), considerando a los territorios como "socialmente vaciables" (Sack, 1986).

Conviene subrayarlo: la minería transnacional demanda el control integral del territorio donde se asienta para cumplir con sus objetivos extractivos. No obstante, casi como una regla politológica, a cada intento de dominación suele contraponerse alguna acción de oposición. Tales resistencias, así como las reacciones de los Estados, será la última de las pautas que se expondrán en relación con el extractivismo minero en América Latina.

\subsection{Cuarta pauta: La conflictividad persistente}

El extractivismo minero ha generado una plétora de depredaciones y estragos. En la médula de esos procesos se localiza aquello que Porto Gonçalves (2001) denominó como "tensión de territorialidades", esto es, el antagonismo de modos de apropiación del espacio. La construcción y recreación de los espacios propician conflictos, pues como observa Enrique Leff (2003) la distribución de valores de uso y de valoressignificaciones asignados a los bienes conlleva luchas de poder. Y si alguna actividad ha acentuado recientemente las luchas de poder en América Latina, esa es la megaminería.

Efectivamente, desde finales de la década de 1990 las bases de datos reportan aumentos en el número de los conflictos vinculados con la minería en América Latina. Por ejemplo, el "Atlas of Environmental Justice" (EJOLT) registra un incremento de los conflictos mineros a partir de 1997 (Villegas, 2014: 10). Tales estadísticas coinciden con la base de datos del Observatorio de Conflictos Mineros de América Latina (OCMAL), donde también se apunta el incremento de los conflictos mineros a partir de 1996 (Villegas, 2014: 11). En datos correspondientes a mayo de 2016, el EJOLT contabiliza alrededor de 218 conflictos vinculados a la minería en Mesoamérica y Sudamérica. Por su parte, el OCMAL reconoce 210 conflictos que afectan a 335 comunidades de la región ${ }^{21}$.

Los datos anteriores coinciden con las cifras nacionales. Por ejemplo, del total de los conflictos registrados en Chile en mayo de 2016, el 77\% de ellos corresponden a los sectores de energía y minería ${ }^{22}$. Del mismo modo, el $66 \%$ de los conflictos socioambientales observados en Perú en julio del 2015 estaban relacionados con la

\footnotetext{
${ }^{21}$ Véase los mapas de cada base de datos. Del EJOLT ver URL: <http://ejatlas.org/>. [Consultado el 12-03-17] y de OCMAL ver URL: <http://mapa.conflictosmineros.net/ocmal_db/>. [Consultado el 12-03-17].

22 Consúltese el mapa en URL: <http://mapaconflictos.indh.cl/>. [Consultado el 18-04-17].
} 
minería $^{23}$. Se documenta entonces una correlación muy alta entre concesiones mineras y conflictos, como en Guatemala, donde 78 de los 101 municipios con licencias mineras (es decir, el 77\%) presenta algún conflicto (ICEFI, 2014: 30).

Estos conflictos se han catalogado como socioambientales (Svampa, 2012), ecológico distributivos (Martínez-Alier \& O'Connor, 1996) o de justicia ambiental (Urkidi \& Walter, 2011). A pesar de la variedad de rótulos, se coincide en que estos conflictos emergen por desigualdades en el acceso, control y distribución del territorio y sus recursos.

En cuanto a la composición, articulación y dinámicas de los movimientos sociales, si bien el sustrato indígena está presente de forma copiosa ${ }^{24}$, es factible caracterizar a su integración como plural, a su ensamblaje como multiescalar y a sus repertorios de acción colectiva como multicondensados.

Por el lado de los movimientos, éstos se constituyen por una variedad de integrantes tales como indígenas, campesin@s, sacerdotes, estudiantes, organizaciones diversas (ambientales, productivas, religiosas, de derechos humanos, de cooperación al desarrollo) y en algunos casos hasta de gobiernos locales, lo que pluraliza su composición y obliga a complejizar el análisis de la conflictividad para superar el binomio comunidades/organizaciones sociales vs. gobiernos/empresas, que no siempre se repite, ni a nivel nacional ni regional, en los países latinoamericanos (por ejemplo, en Colombia, Costa Rica, El Salvador, Guatemala o Panamá).

Otra característica de los movimientos socioambientales es que surgen de un problema concreto y desde un nivel local pero tienden a articularse con organizaciones y redes nacionales, regionales e internacionales ${ }^{25}$, fortaleciéndose así con posicionamientos públicos, recursos técnico-materiales, dispositivos jurídiconarrativos y legitimidad.

Uno de los factores aglutinantes de la diversidad opositora al extractivismo es el discurso, con más precisión, las interpretaciones, significados y símbolos que justifican la acción colectiva, lo que en la literatura especializada se conoce como "marcos cognitivos"26. Entonces, ha ocurrido un proceso de enmarcamiento discursivo alrededor de nociones relacionadas con el medioambiente, lo que Maristella Svampa (2012) cataloga como "giro ecoterritorial", esto es, "la emergencia de un lenguaje común que da cuenta del cruce innovador entre la matriz indígena comunitaria, la defensa del territorio y el discurso ambientalista" (Svampa,

23 Fuente: Defensoría del Pueblo, radiografía de conflictos sociales. Disponible en URL: $<$ http://www.defensoria.gob.pe/blog/defensoria-del-pueblo-registro-209-conflictos-sociales-en-julio/>.

[Consultado el 21-08-17].

24 Como observan Joan Martínez-Alier y Mariana Walter, según la base de datos de EJOLT, en Latinoamérica los pueblos indígenas están presentes en alrededor del 50 por ciento de los conflictos ambientales (Martínez-Alier \& Walter, 2015: 90).

25 Para conocer un listado reciente de los colectivos y redes, tanto nacionales como internacionales, se recomienda revisar el directorio "aliados contra el modelo extractivo minero", elaborado por la organización Otros Mundos Chiapas, disponible en la siguiente $<\mathrm{http}$ //otrosmundoschiapas.org/materiales/docs/pdf/manuales/mineria/mineria_cap12_directorio.pdf $>$. [Consultado el 21-08-17].

26 Dentro de la teoría de movilización de recursos el marco cognitivo es un sistema teórico que analiza los símbolos, discursos y significados que los movimientos otorgan a su derredor. El "análisis de los marcos cognitivos" (frame analysis) considera que los movimientos definen estratégica y conscientemente una situación a través de procesos enmarcadores con miras a facilitar la acción colectiva. 
2012: 22). Según Walter \& Urkidi (2015), los marcos de interpretación de la realidad que justifican el accionar de estos movimientos reflejan lo que se ha identificado como las dimensiones clave de la justicia ambiental: el reconocimiento, la distribución y la participación (Schlosberg, 2007).

Pero si los marcos cognitivos agrupan a los diversos antiextractivismos, su repertorio de acción colectiva reafirma su pluralidad, pues su catálogo de prácticas de protesta ha sido misceláneo y multicondensado, oscilando entre los tipos de acción colectiva que se clasifican como convencional, la alteración del orden y las confrontaciones directas, incorporando así tres propiedades: el desafío, la incertidumbre y la solidaridad (Tarrow, 2004: 135-153).

Para manifestar sus posturas, los individuos y grupos antiextractivistas han realizado acciones como foros, asambleas, publicación de desplegados, marchas, bloqueos carreteros, clausuras simbólicas de minas, plantones en sedes de poderes públicos y embajadas, escenificaciones dramáticas, huelgas de hambre, declaratorias de territorios libres de minería (en Argentina, El Salvador, Guatemala, Honduras, México y Uruguay), y las consultas comunitarias o referéndums (en Argentina, Colombia, Ecuador, Guatemala, Perú y Uruguay), así como acciones más del ámbito institucional, como audiencias públicas, controversias jurídicas y propuesta de leyes.

La pluralidad en su composición, su articulación en diversos niveles, su enmarcamiento discursivo y la variedad de sus repertorios ha permitido que los movimientos de justicia ambiental se desplacen y articulen en diversas escalas tanto geográficas como contingentes ${ }^{27}$.

Como contraparte, los actores que han promovido el extractivismo minero son por lo general gobiernos centrales y empresas mineras, pero también hay casos donde también actúan miembros de las comunidades que aceptan los beneficios económicos de la minería. En términos de respuesta a los repertorios de acción de los movimientos socioambientales, específicamente los gobiernos que apoyan al modelo extractivista suelen responder a los opositores minimizando sus preocupaciones, desacreditando sus discursos, penalizando sus acciones y reprimiendo sus movilizaciones, lo que se conoce como criminalización de la protesta social.

La criminalización de la protesta social funciona como "un mecanismo de control social para neutralizar o inhibir cualquier conducta-manifestación que pueda poner en riesgo o que cuestione las expresiones de poder imperantes y el modelo de desarrollo definido desde el Estado" (OCMAL, 2011: 90-91). Las acciones de disuasión de la protesta social vía la criminalización ocurren en diferentes ámbitos interrelacionados: el discursivo, el judicial, el administrativo y hasta la militarización y la acción policial (OCMAL, 2011) ${ }^{28}$.

La criminalización se inicia con la descalificación de los discursos y de las acciones presentando a los opositores a la minería, presentándolos como cegados por

27 Retomando a Helga Leitner, Eric Sheppard y Kristin Sziarto, la escala se concibe como "una construcción relacional, vinculada al poder y disputada, en la cual los actores se involucran estratégicamente, para legitimar o desafiar relaciones de poder existentes." (Leitner et al., 2008: 159). Un caso que ejemplifica la multiescalaridad de los movimientos socioambientales es el de las consultas comunitarias contra la minería, el cual es ampliamente analizado en (Walter \& Urkidi, 2015).

28 El Observatorio de Conflictos Mineros de América Latina (OCMAL) divide la criminalización de la protesta social en amenazas, asesinato/atentado, judicialización y uso de la fuerza. En datos del 24 de febrero de 2016 , la OCMAL contabilizaba 118 casos. El mapa de criminalización se puede consultar en URL: $<$ http://criminalizacion.conflictosmineros.net/index.php/reports $>$. [Consultado el 29-04-16]. 
un radicalismo ambiental o con ideas arcaicas que obstaculizan las inversiones extranjeras y, por ende, el desarrollo del país. El asunto crítico es que los estereotipos tienen un correlato jurídico. Así, los estigmas de delincuentes o saboteadores tienen una correspondencia legal en figuras penales como "sabotaje", "terrorismo", o "asociación ilícita", lo cual también se ha utilizado como instrumento para confrontar a los movimientos de justicia ambiental (Justicia Viva e IDL, 2012).

Recientemente en los países latinoamericanos ha habido una tendencia a adaptar sus marcos legales para criminalizar las protestas sociales (OCMAL, 2011: 20). Por ejemplo, en Bolivia, la Ley 367 del 2013 penaliza hasta con 8 años de cárcel el "avasallamiento" de las concesiones mineras. En Ecuador la mayoría de las acusaciones a las que se enfrenten los líderes antiextractivistas se basan en dos artículos del Código Penal: el 158 (referido al sabotaje) y el 160 (sobre el terrorismo). Además, en Chile, México, Panamá y Paraguay se han adoptado o propuesto modificaciones a los códigos penales que incluyen o fortalecen tipologías factibles de aplicarse a los movimientos socioambientales, como ataques a las vías de comunicación, secuestro, terrorismo y vandalismo (Villegas, 2014).

Otra de las acciones de disuasión que se ha utilizado es la represión. Esto es, el requerimiento de las fuerzas públicas (policiales o militares) para sofocar los actos de protesta social. En un reporte de la organización internacional Global Witness ${ }^{29}$ se contabilizaron 1.024 asesinatos de activistas medioambientales en el periodo 2002-2014. Entre los 8 países donde se había cometido el 89\% de esos homicidios (es decir, 913), se encontraban 6 latinoamericanos: Brasil, Colombia, Honduras, México, Perú y Guatemala. Los datos de represión, violación a los derechos humanos y asesinatos vinculados al extractivismo de cada país son elocuentes. Por ejemplo, en Colombia se han documentado casos donde han participado las fuerzas militares o paramilitares para desalojar de sus tierras a las poblaciones en conflictos relacionados con las industrias extractivas (OCMAL, 2011: 101). Organizaciones colombianas de derechos humanos calculan que el extractivismo minero ha ocasionado 5.195.620 desplazados, 50.000 desaparecidos y 150.000 casos de tortura (Daumas, 2013: 54). En Perú, de 2006 a 2012 se contabilizan 206 muertos por conflictos sociales relacionados con empresas extractivas (Villegas, 2014: 56).

La conflictividad persistente, la apropiación territorial, la asistencia institucional y la irrupción de la minería transnacional configuran un modelo de extractivismo minero en América Latina que, entre tantas otras, conlleva una lectura política neurálgica: la de la democracia.

\section{Democracia contingente, extractivismo minero interpelado}

No vamos a organizar una fuerza politica que dispute el poder, sino que organice una inversión del poder: que el que mande, mande obedeciendo

EZLN

Según el modelo expuesto, para examinar críticamente al extractivismo minero en América Latina debe considerarse la imbricación de variables económicas, jurídicas,

29 Disponible en URL: <https://www.globalwitness.org/en/about-us/annual-reviews/>. [Consultado el 12-03-17]. 
administrativas, sociales y ambientales que intervienen como detonantes y derroteros del fenómeno. Sin embargo, el enfoque del presente análisis es que las variables anteriores se vertebran explicativamente bajo la efigie de la esfera política. En otras palabras, que si bien lo económico puede ser el germen del extractivismo minero, lo jurídico su aseguramiento, lo administrativo su implementación, lo social su notoriedad y lo ambiental su gravedad, es en los actores, ideologías, instituciones y procesos relacionados con el poder político donde se halla la cohesión y puesta en práctica de esas variables. Pero decir poder político entraña decir también las resistencias que se forjan en su contra. Por eso, en este apartado se interpela al extractivismo minero desde el campo contingente de las decisiones colectivas por antonomasia: la democracia.

Aunque es un término nodal de la teoría política, no existe una definición incontestable sobre la democracia, constituyendo así un "concepto esencialmente controversial"; esto es, aquel que conduce a una serie continuada de discusiones sin acuerdo sobre su correcto uso (Gallie, 1956). Entonces, democracia emerge como un concepto turbulento y una categoría inasible, que inclusive resulta ambigua en su etimología ${ }^{30}$. Por historia, axiología y praxis, la democracia es un concepto tan polisémico como disputado.

Si bien se han confeccionado varios modelos ${ }^{31}$, sobre la democracia predomina una concepción que se ha catalogado como hegemónica (Avritzer \& Santos, 2004), que la define como una entidad política (forma de gobierno o régimen político) estructurada en torno a fundamentos del liberalismo ${ }^{32}$. Esta impronta será determinante para instaurar los tres cimientos medulares de la concepción moderna de la democracia: 1) forma o método de conformar y ejercer el poder político que 2) se fundamenta en principios liberales (el individuo, la libertad como no intromisión - libertad negativa en términos de Isaiah Berlin-, las garantías individuales, el orden, la razón y la ley) y 3) se hace practicable con la representación y las elecciones $^{33}$. Esta concepción se puede caracterizar como democracia liberalrepresentativa-procedimental.

En el caso de América Latina, la democratización verificada a partir de los años $1970^{34}$, implicó en términos generales la creación o reforma de instituciones garantes

30 Usualmente se reconoce que la palabra democracia es producto de la conjunción de dos vocablos, demos y kratos, que se han traducido como poder/gobierno (kratos) del pueblo (demos). No obstante, como analizan Álvarez Garro (2013) y Arblaster (1991), de la palabra kratos no se puede establecer como sinónimos al poder y al gobierno, pues aquel puede existir en múltiples formas sin concretarse en éste. Para el caso de la palabra demos, también resulta ambigua la traducción pues puede significar el colectivo ciudadano de una polis o puede ser utilizado en sentido peyorativo para definir a la muchedumbre.

31 Como no podía ser de otra manera, existen cuantiosos modelos de democracia. Estos modelos van desde los que se erigen a partir de la trilogía de distinciones clásicas ("democracia antigua vs. democracia de los modernos", "democracia directa $v s$. democracia representativa" y "democracia sustantiva $v s$. democracia procedimental") hasta los que son articulados a partir de las cuatro grandes corrientes de la filosofía política contemporánea (liberalismo, republicanismo, comunitarismo, postestructuralismo/posfundacionalismo) o los que se centran en criterios político-normativos (participación, deliberación, justicia). Para conocer autores y textos donde se exponen modelos de democracia, revísese Del Águila et al. (2013), Held (1992), Lijphart (2000), Máiz (2004), Macpherson (1987) y Pérez de la Fuente (2012).

32 Para revisar a profundidad discusiones sobre los planteamientos e historia del liberalismo, se sugiere revisar las siguientes fuentes bibliográficas: Arditi (2009), Rawls (2003) y Sandel (2000).

33 En relación con la vinculación entre el liberalismo y la democracia, se recomienda consultar Álvarez Garro (2013), Bobbio (2006), Macpherson (1987), Mouffe (2003) y O’Donnell (1998).

34 Proceso catalogado por Daniel Zovatto como "una transición doble: del autoritarismo a la democracia y de economías fuertemente intervenidas por el Estado y cerradas a economías abiertas y orientadas al mercado". 
de un sistema electoral y una competencia partidaria efectivas. A decir de Norbert Lechner, se optó por una definición mínima de democracia que configuró regímenes electorales con manejos tecnocráticos del poder político (Lechner, 2003).

Según lo analizado previamente, el extractivismo minero en América Latina cuando no ha producido, ha profundizado desigualdades económicas, exclusiones sociales e injusticias ecológicas que han ahondado las asimetrías políticas por triplicado. Primero, porque su implantación ha sido escoltada de mecanismos plutocráticos, conductas leoninas, relaciones clientelares, tráfico de influencias y opacidad de información ${ }^{35}$. Segundo, porque se ha opuesto a la deliberación realizada fuera de los términos establecidos por el propio extractivismo, resultando de ello la limitación y hasta la clausura de los espacios y las formas de participación ciudadana. Y tercero, porque cuando los movimientos socioambientales han desplegado sus repertorios de acción colectiva, en donde surgen múltiples prácticas participativas (consultas, audiencias públicas, referéndums, etcétera), la respuesta común ha sido la criminalización de la protesta social.

Así, el extractivismo minero fustiga un doble cuestionamiento a la democracia liberal-representativa-procedimental: hacia la representación y hacia los fundamentos liberales. Por el lado de la representación, ésta se cuestiona seriamente cuando quienes accedieron a cargos populares mediante procesos electorales no sólo ignoran o estigmatizan las posturas de los ciudadanos movilizados contra la megaminería, sino que además imponen sus políticas favorables al extractivismo bajo el argumento de que son benéficas para la nación.

Esta degeneración o invalidación de la representación evidencia la persistencia de lo que Guillermo O’Donnell (1997) catalogó como "democracias delegativas", esto es, regímenes políticos donde el ganador de las elecciones se asume como la encarnación de todos los intereses de la nación y, por lo tanto, revestido de poderes y representaciones absolutas que lo eximen de rendir cuentas, limitando así la eficacia de los contrapesos institucionales, los controles políticos y los espacios para los debates y las denuncias. Como asienta Eduardo Gudynas, "cuanto más delegativa es una democracia, más se facilita la implantación de los extractivismos" (Gudynas, 2014).

En relación con los fundamentos liberales, la democracia es refutada por una tergiversación doble: por un lado, la negación y/o limitación de los derechos, principios y mecanismos liberales y, por contraparte, el uso discrecional de los mismos para sostener al extractivismo minero. Así, mientras que en el marco de la megaminería se vulneran libertades y derechos como a la información, a la participación, al medio ambiente, a un juicio justo y hasta a la vida, al mismo tiempo

\footnotetext{
Además, en algunos países, sobre todo los de Centroamérica, la transición también implicó pasar de la guerra a la paz (Zovatto, 2001: 143).

35 En un informe reciente se identifican cuatro mecanismos primordiales de secuestro de la democracia en América Latina: 1) influencia en la definición de políticas, leyes o marcos regulatorios; 2) corrupción; 3) clientelismo, y 4) control de los medios de comunicación (Oxfam, 2015: 11). Todas estas formas se han registrado dentro del extractivismo minero latinoamericano. Por ejemplo, en relación con las reformas legislativas favorables a la minería se ha indicado que "Generalmente, este tipo de acomodaciones legislativas está acompaña de tráfico de influencias y corrupción." (OCMAL, 2015: 100). Denuncias similares sobre estos y otros mecanismos de "secuestro de la democracia" en el sector minero se pueden revisar en: ALOP (2015), Antonelli (2009), CIDSE (2011), García (2015), Gudynas (2014), Hernández Morales (2014), Lichtensztejn (2012), Machado (2011), OCMAL (2011), RRI (2013), Svampa (2012) o Villegas (2014).
} 
los gobiernos invocan al Estado de derecho para justificar la implantación del extractivismo minero y la criminalización de la protesta social:

Existe casi unanimidad en que una genuina democracia debe inspirarse en un principio de mayoría relativa o moderada. En cambio, los extractivismos se imponen excluyendo las sensibilidades, derechos e intereses de minorías locales. Incluso el recurso a la fuerza se justifica diciendo, por ejemplo, que una "minoría" no puede impedir el desarrollo de "toda" la nación [...] Se apela al secretismo y la confidencialidad en las negociaciones con grandes empresas extractivistas. [Y paralelamente] se combate o directamente impide votaciones, referéndums o plebiscitos sobre los extractivismos (Gudynas, 2014: 143, 147).

Entonces, el patrón general de la conflictividad minera en América Latina impugna a la democracia liberal tanto en sus valores y sus principios fundacionales, como en sus mecanismos institucionales.

Las pautas del modelo del extractivismo minero latinoamericano cuestionan a la democracia en su concepción hegemónica, es decir, en cuanto entidad política constituida bajo fundamentos liberales. No obstante, los actores, las ideologías y los procesos de la conflictividad derivada del extractivismo minero demandan una lectura crítica de la democracia más allá de su concepción hegemónica, lo cual puede realizarse al incorporar al análisis planteamientos más radicales, como lo es el del posfundacionalismo.

Como se ha analizado (Marchart, 2009), existe un pensamiento político que puede denominarse como posfundacional, posestructuralista o posmarxista. Aunque hay diferencias entre sus exponentes, ésta corriente teórica plantea la crítica a los fundamentos metafísicos afirmando que, si bien son ontológicamente necesarios, es imposible sostener la existencia de un fundamento último, lo cual habilita la pluralidad de fundamentos posibles al tiempo que coloca en un primer plano el carácter contingente de cualquiera de ellos (Yabkowski, 2013: 2).

Según los planteamientos del posfundacionalismo, el encuentro con la contingencia es el momento de lo político por excelencia dado que es el momento ontológico de dar "forma a la sociedad" (Lefort, 2004): es tanto una situación de disolución de los marcadores de certeza como la precondición misma de la politización y la emancipación:

Los individuos tenderán a considerar que su destino es inevitable si suponen que Dios o la naturaleza han hecho el mundo tal cual es. Pero si se juzga que el mundo es el resultado de los "discursos y vocabularios contingentes que los constituyen", la gente quizá tolere su destino con menos paciencia y empiece a desarrollar una actitud más política hacia la construcción de nuevos, aunque siempre sólo contingentes, fundamentos (Ernesto Laclau, cit. en Marchart, 2009: 206-207).

Para el caso del extractivismo minero, los movimientos socioambientales impugnan al modelo extractivista y sus componentes mermándoles su carácter homogeneizante y hegemonizante al tiempo que posibilitan el carácter contingente del propio extractivismo y de los modelos que lo rivalizan. Lo político, entonces, irrumpe como un proceso donde se disputan recursos, significaciones y proyectos. 
Una de las distinciones centrales del posfundacionalismo es la que se plantea entre la política y lo político, vale decir también, entre el poder constituido y el poder constituyente. La política, por un lado, representa el ámbito de la instauración de los fundamentos, de aquellos mecanismos que pretenden extender ese fundamento particular para posicionarlo como uno universal que hegemonice al resto. El poder constituido, entonces, es el resultado de la articulación de dispositivos para postular universalismo, institución, derecho, consenso, orden y certeza en detrimento de los particulares, las interpelaciones, las contingencias, los disensos, los antagonismos y lo imprevisible. Todo ese poder constituido se articula en torno al Estado, sobre todo en su versión liberal: "[De acuerdo al liberalismo], el poder constituyente se agota en el acto de creación estatal, a partir de este evento, el poder constituyente queda subordinado a las reglas del Estado, y por consiguiente el Estado es el lugar de enunciación y creación del poder político" (Sanín, 2014: 68, 133).

A su vez, lo político emerge como la contraparte, la esfera indeterminada de la acción, por eso puede asumir las formas de "contingencia", "antagonismo", "libertad" o "indecidibilidad" (Marchart, 2009: 203-204). Illan Wall propone el término aristotélico de potentia (potencialidad) como el elemento definidor del poder constituyente, pues remite a la posibilidad de que la cosa pueda devenir en algo más, según su propia condición (Wall, 2012).

De manera que si lo político está asociado con el poder constituyente y lo jurídico con los poderes constituidos, y el poder constituyente está definido por el poder de establecer todo paradigma posible de lo político (Agamben, 1998), donde lo político carece de sentido como obra del poder constituido y sólo existe como creación del poder constituyente (Sanín, 2014: 136).

Es en este polo donde ocurre una subjetivación política ${ }^{36}$ que pone en evidencia "las contradicciones y las injusticias que forman parte de un sistema político que bajo las banderas de la libertad y la igualdad se encarga de ocultarlas" (Reano, 2009: 319).

Para el tema del presente artículo, la política —el poder constituido- se hallaría en las maniobras institucionales que han pretendido instituir el extractivismo minero en la región. Mientras que lo político - el poder constituyente- sería todo lo que palpita en las interpelaciones al modelo extractivista evidenciando su núcleo hegemónico y habilitando simultáneamente otros senderos posibles fuera de ese modelo.

Precisamente, este momento contingente e imprevisible, y por lo tanto emancipatorio, es para los posfundacionalistas el de la democracia, puesto que ella denota una manera de ser de lo político (Rancière, 2007b). Entonces, la democracia es el nombre que adquiere ese momento en que el poder constituyente se pone en acción denotando la imposibilidad de constituir la sociedad como un conjunto cerrado, totalizado y último:

La democracia es el régimen que solo puede establecerse a través de una interrogación permanente sobre sí mismo; régimen que jamás estará

36 Siguiendo a Jacques Rancière, la subjetivación política es aquella que tiene por resultado la creación de una multiplicidad que no estaba contada en la constitución policial de la comunidad, y por lo tanto, es una multiplicidad que resulta contradictoria, cuestionando la aparente naturalidad en la distribución de las posiciones (Rancière, 2007b: 52-53). 
definitivamente dado ni enteramente logrado por las instituciones que lo fundan, que permanece siempre marcado por una forma de indeterminación primera (Rosanvallon, 2007: 168).

Como lo postula Jacques Rancière, el demos es la parte de los que no tienen parte, por eso, la democracia no significa una sociedad por gobernar, ni un gobierno de la sociedad, sino esa ingobernabilidad sobre la cual todo gobierno debe descubrirse fundado. Lo político, entonces, no tiene un lugar en la organización de la sociedad porque es justamente una fuerza que disputa la asignación de los lugares y de los sujetos que los ocupan (Rancière, 2007a). Así concebida, la democracia es la interpelación, la imprevisibilidad y la indecidibilidad derivada del demos. La democracia sería, en términos de Jacques Derrida, "algo que está por venir" (Derrida, 1994: 3). Y Sanín abunda:

Tal como lo establece Jean Luc Nancy (2009), la democracia sería una demoarquía si el poder del pueblo sólo establece un origen (arche) al que debe ser leal y el cual lo supera y limita. [...] La CRACIA de democracia significa poder ilimitado, fundante [no fundado] y siempre presente, cuya categoría definitiva es una "potencia" que no puede ser reducida a un marco que lo contenga y determine (Sanín, 2014: 133).

La democracia entraña la lucha contra el poder constituido porque si éste supone las pretensiones de orden hegemónico por un particular que se postula como universal, aquella significa su contestación por un demos amorfo, abierto y ambulante que, cuando da signos vitales, revela las contradicciones del poder constituido. La democracia es así "una amenaza constante al poder constituido" (Sanín, 2014: 54).

Como puede inferirse, esta concepción de la democracia difiere ampliamente de la concepción hegemónica porque cuestiona los fundamentos en los que ésta se ha asentado, como su desestimación del conflicto y del antagonismo.

En el liberalismo existe la tenencia a asociar la política a visiones moralistas, racionales y universalistas que consideran lo plural como algo armonioso, negando así la visión conflictiva del pluralismo y lo político en su dimensión antagónica (Mouffe, 1999). Si bien el liberalismo "reconoce" la pluralidad y las diferencias, "éstas son reconocidas en tanto no generen conflicto. Si generan conflicto, se ubican como diferencias fuera de la ley y por ende, es legítimo combatirlas" (Álvarez Garro, 2013: 196).

En la concepción hegemónica de la democracia el disenso y el conflicto son calificados como situaciones inmorales, irracionales y anormalidades que deben sujetarse a la primacía del orden y la estabilidad. Esa operación de exclusión y captura es realizada por el régimen jurídico (el Derecho, las instancias que lo implementan y las narrativas que lo introyectan) a partir del ideal de coherencia y consistencia. Se trata de la reducción del disenso y el conflicto a códigos y procedimientos; una forma de apaciguar las anomalías, contener innovaciones, tratar lo sorpresivo como patológico y ejercer control sobre cuerpos y cosas (Sanín, 2014: 165-166).

El régimen jurídico es el basamento y el dispositivo central del Estado liberal, pero también es precepto constituyente y condición de funcionamiento de la 
democracia liberal pues el respeto a las reglas es un principio básico de la concepción hegemónica de la democracia. Y al mismo tiempo, las Constituciones políticas, piedras fundantes y tótems de los regímenes jurídicos, reconocen a la democracia liberal-representativa-procedimental como la forma legítima de administrar a sus sociedades. Así, entre democracia liberal y régimen jurídico existe no sólo correspondencia sino complicidad. La una requiere del otro para instituirse, éste precisa de aquella para legitimarse; ambos convergen en su pretensión medular de la defensa del orden y la salvaguardia de la estabilidad.

El punto es que, según el posfundacionalismo, ese concubinato tergiversa los orígenes, pues el poder constituido que deriva del poder constituyente supera y se superpone a éste. El Estado, el Derecho y sus instituciones derivadas cimientan su legitimidad en un demos al que procuran neutralizar al otorgarle personalidad (márgenes legales de presencia y acción) dentro de su ordenamiento jurídico. Se invierte así la ecuación: el poder constituyente no sólo ya no es creador del poder constituido, sino que ahora existe en virtud de que es nombrado por éste. La triada Estado-Derecho-Democracia instituye así los espacios, los actores y los procesos acreditados, racionales y válidos. De este modo, la potencialidad se convierte en sujeción, la contingencia en delimitación y el demos en electorado.

En este punto resulta pertinente retomar el caso de la conflictividad derivada del extractivismo minero en América Latina. Como se examinó, por un lado se ha configurado y pretendido imponer un régimen de verdad que procura amparar el modelo extractivista a pesar de sus contradicciones y las perturbaciones que genera. Pero, por otro lado, debido precisamente a esos trastornos, han emergido tanto organizaciones como movimientos plurales y multiescalares que impugnan a la megaminería, mostrando así los límites de la democracia liberal pero también posibilitando el surgimiento de un poder constituyente.

Como se analizó, la configuración de un régimen internacional promocionó al extractivismo minero en la región, el cual a su vez ha sido implementado al interior de los países latinoamericanos mediante facilidades normativas, administrativas, tributarias y hasta discursivas. Arropada de los artilugios del poder constituido, la megaminería se ha correlacionado con términos como Estado de Derecho, Nación y progreso. No obstante, los movimientos de justicia ambiental han cuestionado tales maniobras discursivas, han criticado el modelo extractivista, han objetado la intromisión de las empresas mineras en sus territorios, han contradicho los beneficios que ellas postulan y han reclamado su participación en las decisiones que les afectan y el acatamiento a las decisiones comunitarias. Estas organizaciones y movimientos han actuado como un poder constituyente que refuta de múltiples formas al poder constituido.

En el marco del extractivismo minero, la democracia liberal ha sido puesta en tela de juicio. Primordialmente, porque los actores, instancias, procesos y discursos de la política institucional se muestran rebasados: el poder ejecutivo, el poder legislativo, los partidos políticos o el sistema electoral se han revelado como esferas insuficientes y hasta prescindibles para resolver justa y legítimamente los conflictos socioambientales.

Ello es así porque los problemas del poder y la configuración de las resistencias tienen lugar más allá de lo institucionalizado, en los intersticios de la vida cotidiana. La contaminación, la pérdida de biodiversidad o la desestructuración de la vida 
comunitaria no ocurre en las solemnes sedes de los poderes constituidos, sino en las localidades, los ecosistemas y los cuerpos de las personas.

La política institucional, regulada y monopolizada por entidades prefiguradas, cede su espacio a la emergencia de un campo político (Bourdieu, 2001), es decir, al espacio de interacciones, coincidencias y conflictos que remite a la esfera de las luchas hegemónicas por el poder (Dussel, 2006), donde se discuten y resignifican concepciones y prácticas.

Aquí sobreviene lo que parece ser un nudo gordiano por la misma cuerda, la de la democracia. Porque, por un lado, si el carácter más democrático de la acción política ocurre cuando los acallados alzan su voz y muestran su inconformidad (Reano, 2009: 327); si el objetivo de una política democrática es multiplicar los espacios en los que las relaciones de poder estarán abiertas a la contestación (Mouffe, 2003); si la democracia es ruptura con instituciones tradicionales para crear nuevas determinaciones, normas y leyes (Avritzer \& Santos, 2004: 17), y si hay una caracterización intrínsecamente democrática de la política en la medida que se autodetermine como espacio de emancipación sustraído de las figuras consensuales del Estado (Badiou, 1998: 9), entonces las organizaciones y los movimientos sociales que enfrentan al extractivismo minero en América Latina recrean a la democracia, no sólo al evidenciar la división inherente de toda sociedad política (Lefort, 2004), sino también al reconquistar la demodiversidad ${ }^{37}$ (Avritzer \& Santos, 2004).

Pero, por otro lado, esa división evidenciada y esa demodiversidad expuesta provocan la reactivación inmediata del núcleo racional del poder constituido para recuperar la estabilidad con estricta observancia al Derecho. Así, las instituciones de la democracia liberal-representativa-procedimental buscan contener el disenso y articularlo a mecanismos del consenso (Reano, 2009: 315). Se trata de determinar quién y qué se incluye dentro del diálogo, limitar lo que es jurídicamente negociable e impedir salirse de los protocolos del derecho para bloquear las oportunidades de contestación relegando el antagonismo a calificaciones estrictas en las que se desarticulan y aplazan las demandas populares y se retiene la posibilidad de que las partes débiles usen un lenguaje que no sea el de la parte fuerte de la institucionalidad (Sanín, 2014: 48). Y si las partes en desacuerdo se resisten a entrar en esa lógica, desde el poder constituido se les cataloga como elementos espurios condenados a reconsiderar su postura bajo la amenaza de la "implementación del Estado de Derecho". He aquí la génesis de la criminalización de la protesta social que se examinó en páginas previas.

Y es así como la democracia emerge como una contradicción. Porque es simultáneamente la acusada y la fiscal, el problema y la solución, la constituida y la constituyente. Esta paradoja democrática (Mouffe, 2003) consiste en que el principio del poder del pueblo emerge en un marco simbólico estructurado por el liberalismo, donde se evidencia la imposibilidad de limitar dicho poder a pesar de los intentos por contenerlo.

En el contexto del extractivismo minero, la paradoja democrática se patentiza al observar que la minería a gran escala en América Latina ha sido tanto implantada como resguardada por gobiernos y poderes públicos engarzados en una

37 "Por demodiversidad entendemos la coexistencia pacífica o conflictiva de diferentes modelos y prácticas democráticas" (Avritzer \& Santos, 2004: 40). 
institucionalidad liberal-democrática pero que son esos mismos gobiernos y poderes públicos quienes, en su mayoría, repudian, restringen y repelen los movimientos socioambientales y sus expresiones contra el extractivismo minero. Las mismas instituciones y procesos democráticos que se esgrimen para legitimar el extractivismo minero son las mismas instituciones y procesos que suelen rechazar a los actores, discursos y procesos que se oponen al extractivismo minero.

La conflictividad emanada del extractivismo minero exhibe extensamente las contradicciones, confinamientos y artificios de la democracia liberal-representativaprocedimental en América Latina. Pero simultáneamente contiene prácticas y discursos provenientes de organizaciones y movimientos que, mientras interpelan al modelo extractivista y a los actores e instituciones que lo han abrazado, muestran signos de un poder constituyente que todavía palpita en la región.

\section{Conclusiones: excepciones, persistencias y desafíos}

No soy un ingenuo, ni un utópico; sé que no habrá una gran revolución. A pesar de todo, se pueden hacer cosas útiles, como señalar los límites del sistema.

Slavoj Žižek

El modelo del extractivismo minero expuesto en el presente artículo configura las líneas generales del fenómeno en América Latina pero no se postula como un esquema que engloba exhaustiva y monolíticamente el tema en su totalidad. No es así puesto que en la región se han registrado eventos que si no contradicen, cuando menos cuestionan las cuatro pautas planteadas como basamentos del modelo. Básicamente, son tres las excepciones a los paralelismos del extractivismo minero.

La primera excepción son las tasas de ganancia que los países han obtenido de la megaminería, pues éstas han oscilado entre porcentajes considerables y nimios. Por ejemplo, en la contribución de la minería al PIB entre los años 2000 y 2012, los países que mayores aportaciones recibieron de la minería fueron Chile $(12,63 \%)$, Ecuador $(8,93 \%)$, Perú $(7,33 \%)$ y Bolivia $(6,06 \%)$. A su vez, los países donde la minería concurrió prácticamente como un sector testimonial en el PIB fueron Brasil (0,76\%), Honduras y México (ambos, con un 0,83\%) (Acquatella, 2014: 26).

Una segunda variable que tampoco es una pauta en el extractivismo minero latinoamericano tiene que ver con casos donde el poder judicial se ha involucrado activamente en los conflictos, dando como resultado la interrupción de proyectos mineros bajo los argumentos de afectaciones ambientales, incumplimientos administrativos o ausencia consulta previa. Esta "judicialización" ha ocurrido particularmente en Chile y Colombia.

Por último, una tercera excepción son casos donde se han prohibido actividades extractivas mineras, inclusive en todo el país. Todos ellos son casos transcurridos en Centroamérica. En Panamá, se prohibió el otorgamiento de concesiones de exploración y explotación minera en la Comarca Ngäbe-Buglé. En El Salvador existe una moratoria "de facto" sobre la minería a cielo abierto, aunque aún continúan proyectos en fase de exploración. En Costa Rica, la Asamblea Legislativa aprobó en el 2010 una ley que prohíbe en su territorio la minería a cielo abierto.

A pesar de su presencia, las tres excepciones no anulan la existencia del extractivismo minero, ni el modelo presentado, ni mucho menos el núcleo geopolítico y 
económico-político que se ha profundizado con esa práctica: la participación de América Latina en el concierto internacional como proveedor de materias primas.

Según las Bases de Datos y Publicaciones Estadísticas de la CEPAL (CEPALSTAT) del año 2014, en la primera década del siglo XXI América Latina se sumió más en la dependencia de la exportación de los productos primarios: en un periodo de 12 años (de 1999 a 2012) los países que más aumentaron su dependencia fueron, en ese orden, Bolivia, Brasil, Colombia y Uruguay. A su vez, los países donde los productos primarios representaron más del $90 \%$ de sus exportaciones fueron Venezuela (95,5\%), Bolivia (95,1\%), Ecuador $(91,2 \%)$ y Paraguay $(91,2 \%)$ (Villegas, 2014: 24). Un inventario sobre dichos productos indica que desde mediados de la década del 2000 los sectores extractivos despuntaron como relevantes, pues en la minería y los hidrocarburos se presentaron porcentajes superiores al 50\% de las exportaciones totales (Acquatella, 2014: 48). En datos del 2014 América Latina proveyó el $42 \%$ de la producción mundial de plata, el $41 \%$ de la de cobre, el $18 \%$ de la de estaño y zinc, el $12 \%$ de la de oro y el $10 \%$ de la de hierro y plomo (Almonte \& Sánchez, 2016).

Estos datos reflejan, como describe Horacio Machado, distinciones en las geografías de la extracción de los recursos naturales y de su consumo: "se da una clara diferenciación entre los países del Sur y del Norte geopolítico, concentrándose los procesos extractivos en los primeros y los mayores índices de consumo en los segundos" (Machado, 2011: 170). Así, a pesar de que América Latina es uno de los principales proveedores de minerales, la región sólo consume entre el 3\% y el 6\% del total mundial (Machado, 2010: 84-86).

El extractivismo minero, entonces, ha profundizado el modelo primarioexportador y, por ende, la dependencia externa y la colonialidad ${ }^{38}$ en América Latina. Ha sido una reiteración de la subordinación de los países latinoamericanos al capital internacional y los mercados globales que conlleva intrínsecamente relaciones de dominación, colonización y explotación. En esta lógica, los Estados suelen ajustarse a las condicionantes del capitalismo, volviéndose lo que Harvey (2004) nombró "Estados satélite". Así, la soberanía de los Estados queda en entredicho.

A pesar de que a partir del año 2012 se han registrado bajas en los precios de las materias primas, se prevé que se mantendrá el extractivismo minero en América Latina debido tanto a la continuidad de los procesos económicos de China y otras regiones emergentes, como a que los metales aún presentan un amplio margen de ganancia (Almonte \& Sánchez, 2016: 25, 107). Ello se confirma con una nota de finales del 2015 que se refiere planes del Banco Mundial para nuevas inversiones mineras en la región que llegarían a los US\$200.000 millones para el año $2020^{39}$.

Sobre este escenario de excepciones y continuidades del extractivismo minero, emerge ineludiblemente la cuestión de los actores participantes, el proceso de

38 "La colonialidad es uno de los elementos constitutivos del patrón mundial de poder capitalista. Se funda en la imposición de una clasificación racial/étnica de la población del mundo como piedra angular de dicho patrón de poder y opera en cada uno de los planos, ámbitos y dimensiones, materiales y subjetivas, de la existencia social cotidiana y a escala societal" (Quijano, 2007: 93). Para revisar análisis sobre el extractivismo minero relacionados con la colonialidad, revísese Alimonda (2011).

39 Véase Luis Fajardo, "Que le dejó a América Latina la década de bonanza minera que está llegando a su fin?" BBC Mundo, 15 de octubre de 2015. Disponible en URL: $<$ http://www.bbc.com/mundo/noticias/2015/10/151014_economia_decada_bonanza_minera_lf $>$. [Consultado el 3-3-16]. 
formación y la legitimidad de las decisiones colectivas en América Latina. Se trata, más específicamente, del tema de la democracia. Ésta, como ya fue analizado, puede concebirse tanto como una entidad política constituida (concepción hegemónica) o como las esferas contingentes factibles de constituir lo político (concepción posfundacionalista) pero versa perennemente sobre las formas, recursos y acciones (materiales y simbólicas) que atañen a lo colectivo.

El extractivismo minero en América Latina es sí un tema con raigambres económicas, políticas, sociales y jurídicas pero, según se ha esgrimido y argumentado en este texto, apunta contundentemente a una articulación analítica desde la cuestión de la democracia. Esto, gracias a tres razones. Primero, porque el extractivismo minero atañe a la vida en colectivo en todas sus facetas. Como se ha evidenciado en la exposición previa, la implantación de los procesos extractivos de la megaminería ha alterado y puesto en riesgo numerosos ámbitos de la vida humana, social, cultural y política. No se trata de afectaciones monotemáticas ni individuales, sino de agravios que impactan multitemática y colectivamente.

En vinculación con lo anterior, la segunda razón para incluir a la democracia en el análisis del extractivismo minero latinoamericano se debe a que el proceder de éste ha implicado una afrenta a la concepción hegemónica de aquella. Como ya se expuso previamente, la tendencia mayoritaria en la región ha sido que las instancias de la política institucionalizada se han mostrado insuficientes para incluir las posturas contrarias al extractivismo y resolver imparcial y legítimamente los conflictos suscitados. Así, los valores liberales (como la libertad y la igualdad ante la ley) y las instituciones políticas (poderes ejecutivo, legislativo y judicial) han quedado en entredicho en su mayoría al activar o acoplarse a dispositivos discursivos y aparatos estatales que rechazan, contienen y penalizan el disenso emergido en el seno de los movimientos socioambientales contra el extractivismo minero.

Siguiendo con la argumentación, en tercer lugar, bajo el extractivismo minero emerge aquello que Chantal Mouffe denominó "paradoja democrática", pues la irrupción de los movimientos que lo interpelan (un poder constituyente) se ven confinados y hasta castigados por la triada de poderes institucionalizados (poder constituido). La paradoja democrática es, pues, una evidencia de los límites de la democracia en su concepción hegemónica pero al mismo tiempo es también una grieta desde donde se puede avizorar prácticas y discursos de un poder constituyente, que es el núcleo —o debería de serlo - de la democracia. La conflictividad emanada del extractivismo minero es un buen síntoma de los artificios y las posibilidades de regeneración de la democracia en América Latina.

Conviene, entonces, no olvidar que lo que hoy se postula como constituido suele olvidar que está sujeto a la multiplicidad de esas pulsiones que primero palpitan incesantemente pero posteriormente interpelan y pueden derrumbar así como volver a constituir. Son esas dormitaciones e intersticios donde habitan los límites del extractivismo minero. Y donde la democracia en América Latina tiene frente a sí el desafío de mirarse en una radiografía de su situación actual.

\section{Bibliografía}

Acquatella Corrales, Jean (2014) "Rentas del sector minero e hidrocarburos 2000-2013". Comunicación a VIII Jornadas Monetarias, La Paz, Bolivia, 24 de julio de 2014. 
[Disponible

en

URL:

$<$ https://www.bcb.gob.bo/jornadamonetaria/sites/default/files/viiijornada/2_CEPAL.pdf

$>$. Consultado el 30 de mayo de 2016].

Agamben, Giorgio (1998) Homo sacer. Sovereign Power and Bare Life. Stanford: Stanford University Press.

Alimonda, Héctor (coord.) (2011) La naturaleza colonizada. Ecología política y minería en América Latina. Buenos Aires: CLACSO.

Almonte, Hugo \& Sánchez, Ricardo (2016) Hacia una nueva gobernanza de los recursos naturales en América Latina y el Caribe. Santiago: CEPAL. [Disponible en URL: $<$ http://repositorio.cepal.org/bitstream/handle/11362/40157/S1600308_es.pdf?sequence $=1>$. Consultado el 30 de mayo de 2016].

ALOP, Asociación Latinoamericana de Organizaciones de Promoción al Desarrollo (2015) Informe sobre democracia y desarrollo en América Latina 2012-2013. Las organizaciones y movilizaciones sociales por la defensa de los recursos y bienes naturales. Un desafío para la democracia y el desarrollo en América Latina. [Disponible en URL: <http://mesadearticulacion.org/wp-content/uploads/2015/05/INFORMESOBRE-DEMOCRACIA-Y-DESARROLLO-EN-AMERICA-LATINA-

2012_2013_FINAL.pdf $>$. Consultado el 11 de junio de 2016].

Álvarez Garro, Laura (2013) Democracia liberal-procedimental. Un análisis del concepto desde la teoría posfundacional. Tesis de doctorado, Universidad Autónoma de México, sede Iztapalapa.

Álvarez Leguizamón, Sonia (2008) Pobreza y desarrollo en América Latina. El caso de Argentina. Buenos Aires: Universidad Nacional de Salta.

Antonelli, Mirta Alejandra (2009) "Minería transnacional y dispositivos de intervención en la cultura. La gestión del paradigma hegemónico de la «minería responsable y el desarrollo sustentable»", en M. Svampa y M. Antonelli (eds.) Minería transnacional, narrativas del desarrollo y resistencias sociales. Buenos Aires: Biblos, 51-102.

Arblaster, Anthony (1991) La Democracia. México: Alianza.

Arditi, Benjamin (2009) La politica en los bordes del liberalismo. Barcelona: Gedisa.

Avritzer, Leonardo \& Santos, Boaventura de Sousa (2004) "Para ampliar el canon democrático", en B. de Sousa Santos (coord.) Democratizar la democracia. Los caminos de la democracia participativa. México: Fondo de Cultura Económica, 33-69.

Badiou, Alain (1998) "Razonamiento altamente especulativo sobre el concepto de democracia" [Disponible en URL: $<$ http://www.elortiba.org/pdf/Badiou_Razonamiento_sobre_el_concepto_de_Democraci a.pdf $>$. Consultado el 27 de enero de 2016].

Bobbio, Norberto (2006) Liberalismo y democracia. México: Fondo de Cultura Económica.

Bourdieu, Pierre (2001) El campo político. La Paz: Plural.

Bridge, Gavin (2004) "Mapping the Bonanza: Geographies of Mining Investment in an Era of Neoliberal Reform”. The Professional Geographer, vol. 56, núm. 3, 406-421.

Castagnino, Vincent (2006) Minería de metales y derechos humanos en Guatemala. La mina Marlin en San Marcos. Guatemala: Brigadas de Paz Internacionales.

CHA, Christian Aid (2009) Socavando a los pobres. Reformas tributarias mineras en América Latina. [Disponible en URL: <http://www.source-international.org/wpcontent/uploads/2012/11/Undermining-the-Poor-final-spanish.pdf $>$. Consultado el 26 de junio de 2013]. 
CIDSE (2011) La criminalización de la protesta social en torno a la industria extractiva en América Latina. [Disponible en URL: $<$ http://www.pasc.ca/sites/pasc.ca/files/articles/La\%20criminalizaci $\% \mathrm{C} 3 \% \mathrm{~B} 3 \mathrm{n} \% 20 \mathrm{de} \%$ $201 \mathrm{a} \% 20$ protesta $\% 20$ social $\% 20$ en $\% 20$ torno $\% 20 \mathrm{a} \% 201 \mathrm{a} \% 20$ industria $\% 20$ extractiva $\% 20$ en $\% 20 \mathrm{Am} \% \mathrm{C} 3 \%$ A9rica $\% 20$ Latina_Analisis\%20y\%20recomendaciones $\% 20$ junio $\% 202$ 011.pdf $>$. Consultado el 17 de mayo de 2016].

Daumas, Lucile (2013) "Políticas mineras en Latinoamérica: grandes similitudes y diferencias aparentes". Petropress, núm. 30, 52-56. [Disponible en URL: $<$ http://www.cedib.org/wp-content/uploads/2013/01/Politicas-mineras-enlatinoamerica-grandes-similitudes-y-diferencias-aparentes.pdf $>$. Consultado el 19 de mayo de 2016].

Del Águila, Rafael; Vallespín, Fernando; Rivero, Ángel; García Guitián, Elena \& De Gabriel Pérez, José Antonio (2013) La democracia en sus textos. Madrid: Alianza Editorial.

Delgado Ramos, Gian Carlo; Silva Ontiveros, Letizia \& Isla Vargas, Maritza (2013) "Minería y ruralidad en México: regulación, pasivos ambientales y sociedad", en R. Rodríguez Saldaña y J. G. Garza Grimaldo (eds.) La naturaleza con derechos. Una propuesta para un cambio civilizatorio. México: Universidad Autónoma de Guerrero, 179-216.

Derrida, Jacques (1994) "La democracia como promesa”. Entrevista de Elena Fernández con Jacques Derrida. Jornal de Letras, Artes e Ideias, 12 de octubre, 9-10. [Disponible en URL: <http://www.infoamerica.org/documentos_pdf/derrida02.pdf >. Consultado el 15 de junio de 2016].

Dussel, Enrique (2006) 20 tesis de politica. México: Siglo XXI.

Escobar, Arturo (1998) La invención del Tercer Mundo. Construcción y deconstrucción del desarrollo. Bogotá: Grupo Editorial Norma.

Gallie, Walter Bryce (1956) "Essentially contested concepts". Proceeding of the Aristotelian Society, vol. 56, 167-198.

Garay Zarraga, Ane (2014) La minería transnacional en Centroamérica: lógicas regionales e impactos transfronterizos. El caso de la mina Cerro Blanco. Madrid: Paz con dignidad, [Disponible en URL: <http://omal.info/IMG/pdf/mineria_transnacional.pdf $>$. Consultado el 8 de agosto de 2015].

García, Ilse (2015) "Mineras: ¿impunidad con el permiso del Estado?". Sin Embargo [Disponible en URL: <http://www.sinembargo.mx/01-05-2015/1329409>. Consultado el 28 de mayo de 2015].

González, Silvia (2015) Impactos ambientales y en la salud humana de la minería a cielo abierto para la extracción de oro utilizando lixiviación con soluciones de cianuro. [Disponible en URL: $<$ https://www.google.com.mx/url?sa=t\&rct=j\&q=\&esrc=s\&source=web\&cd=1\&cad=rj a\&uact $=8 \&$ ved $=0$ ahUKEwiO-

YDsxenLAhWowYMKHX71D3sQFggaMAA\&url=http\%3A\%2F\%2Fwww.conflictos mineros.net $\% 2$ Fagregar-documento $\% 2$ Festudios-e-informes $\% 2$ Fsustanciastoxicas $\% 2$ Fcianuro $\% 2$ Fimpacto-mineria-concianuro\%2Fdownload\&usg=AFQjCNEr3fBzydQmMfaSqWPIG81380ejfw\&sig2=LZW m9Lm08DF56d6_DcIeyA\&bvm=bv.118353311,d.amc $>$. Consultado el 6 de diciembre de 2015].

Gudynas, Eduardo (2009) "Diez tesis urgentes sobre el nuevo extractivismo. Contextos y demandas bajo el progresismo sudamericano actual”, en VV AA: Extractivismo, política y sociedad. Quito: CAAP (Centro Andino de Acción Popular) y CLAES (Centro Latino 
Americano de Ecología Social), 187-225. [Disponible en URL: $<$ http://www.gudynas.com/publicaciones/GudynasNuevoExtractivismo10Tesis09x2.pdf $>$. Consultado el 3 de diciembre de 2016].

Gudynas, Eduardo (2011) "El nuevo extractivismo progresista en América del Sur. Tesis sobre un viejo problema bajo nuevas expresiones", en VV AA: Colonialismos del siglo XXI. Negocios extractivos y defensa del territorio en América Latina. Barcelona, Icaria, 75-92.

Gudynas, Eduardo (2013) “Extracciones, extractivismos y extrahecciones”. Observatorio del Desarrollo (Montevideo), núm. 18. [Disponible en URL: $<$ http://www.extractivismo.com/documentos/GudynasApropiacionExtractivismoExtrah eccionesOdeD2013.pdf>. Consultado el 20 de abril de 2015].

Gudynas, Eduardo (2014) "Cuando los extractivismos reconfiguran democracias y derechos. Tensiones y contradicciones bajo el progresismo realmente gobernante". Revista Herramienta (Buenos Aires), núm. 54, 139-150. [Disponible en URL: $<$ http://gudynas.com/wp-content/uploads/GudynasExtractivismosDemocraciasDerechosHerramienta14.pdf $>$. Consultado el 11 de junio de 2016].

Harvey, David (2004) “The New Imperialism: Accumulation by Dispossession”. Socialist Register, vol. 40, 63-87.

Held, David (1992) Modelos de democracia. México: Alianza editorial.

Hernández Morales, César Jerónimo (2014) Minería y sobreexplotación de la naturaleza en América Latina: caracterización de la minería contemporánea a través del caso mexicano. Tesis de Maestría, Universidad Nacional Autónoma de México.

Howard, Georgina (2012) "Vive México «boom» minero". Reporte Índigo [Puesto en línea: 20 de septiembre de 2012. Disponible en URL: $<$ http://www.reporteindigo.com/reporte/mexico/vive-mexico-boom-minero $>$.

Consultado el 27 de mayo de 2016].

ICEFI, Instituto Centroamericano de Estudios Fiscales (2014) La minería en Guatemala: realidad y desafios frente a la democracia y el desarrollo. Guatemala: ICEFI. [Disponible en URL: <http://icefi.org/wp-content/uploads/2014/03/mineria-impresion.pdf $>$. Consultado el 20 de noviembre de 2015].

Justicia Viva e IDL (2012) Informe la criminalización de las protestas sociales durante el primer año del gobierno de Ollanta Umala: "De la gran transformación a la mano dura". Lima: Justicia Viva e IDL.

Lamberti, María Julieta (2011) "Una lucha «a cielo abierto». El caso del Frente Amplio Opositor a Minera San Xavier”, en H. Alimonda (coord.) La naturaleza colonizada. Ecología política y minería en América Latina. Buenos Aires: CLACSO, 303-331.

Lechner, Norbert (2003) "Estado y sociedad en perspectiva democrática". Polis. Revista Latinoamericana, núm. 6. [Puesto en línea el 20 septiembre 2012. URL: $<$ http://journals.openedition.org/polis/6442>. Consultado el 27 de enero de 2016].

Leff, Enrique (2003) "La ecología política en América Latina: un campo en construcción”. Sociedade e Estado (Brasilia), vol. 18, núm. 1/2, 125-145.

Leff, Enrique (2008) Discursos sustentables. México: Siglo XXI. [Disponible en URL: $<$ http://colegiodesociologosperu.org/nw/biblioteca/Discursos\%20sustentables\%20$\% 20$ Leff.pdf $>$. Consultado el 30 de enero de 2016].

Lefort, Claude (2004) La incertidumbre democrática. Ensayos sobre lo político. Barcelona: Anthropos. 
Leitner, Helga; Sheppard, Eric \& Sziarto, Kristin (2008) “The spatialities of contentious politics". Transactions Institute of British Geographers, vol. 33, núm. 2, 157-172.

Lichtensztejn, Samuel (2012) "El Fondo Monetario Internacional y el Banco Mundial. Sus relaciones con el poder financiero". Economía UNAM, vol. 9, núm. 25, 14-28. Disponible en

$<$ http://www.economia.unam.mx/publicaciones/nueva/econunam/25/02samuel.pdf $>$.

Consultado el 27 de mayo de 2016].

Lijphart, Arend (2000) Modelos de democracia. Barcelona: Ariel.

Machado Aráoz, Horacio (2010) “«El agua vale más que el oro». Grito de resistencia decolonial contra los nuevos dispositivos expropiatorios”, en G. C. Delgado Ramos (coord.) Ecología política de la minería en América Latina. México: CEIICH, UNAM, 59-96.

Machado Aráoz, Horacio (2011) "El auge de la minería transnacional en América Latina. De la ecología política del neoliberalismo a la anatomía política del colonialismo", en $\mathrm{H}$. Alimonda (coord.) La naturaleza colonizada. Ecología política y minería en América Latina. Buenos Aires: CLACSO, 135-179.

Máiz, Ramón (2004). "Modelos normativos de democracia". Revista Mexicana de Sociología, vol. 66, núm. especial, 25-47. [Disponible en URL: $<$ http://www.jstor.org/stable/3541441>. Consultado el 15 de julio de 2016].

Macpherson, Crawford B. (1987) La democracia liberal y su época. Madrid: Alianza editorial.

Martínez-Alier, Joan \& O’Connor, Martin (1996) "Ecological and Economic Distribution Conflicts", en R. Costanza, O. Segura y J. Martinez Alier (eds.) Getting down the Earth: Practical Applications of Ecological Economics. Washington D.C.: Island Press, 277286.

Martínez-Alier, Joan \& Walter, Mariana (2015) "Metabolismo social y conflictos extractivos" en F. de Castro, B. Hogenboom y M. Baud (coords.) Gobernanza ambiental en América Latina. Buenos Aires: CLACSO, ENGOV, 73-104.

Marchart, Oliver (2009) El pensamiento politico posfundacional. La diferencia política en Nancy, Lefort. Badiou y Laclau. Buenos Aires: Fondo de Cultura Económica.

MME, Ministério das Minas e Energia (2011) Plano nacional de Mineração 2030. [Disponible en URL: $<$ http://www.mme.gov.br/documents/1138775/1732821/Book_PNM_2030_2.pdf/f7cc7 6c1-2d3b-4490-9d45-d725801c3522>. Consultado el 30 de junio de 2016].

Morán, Robert (2013) Preguntas y respuestas sobre minería. Buenos Aires: Greenpeace. [Disponible en

URL: $<$ http://www.greenpeace.org/argentina/Global/argentina/report/2013/cambio_climatico/ Informe-Moran-mineria.pdf $>$. Consultado el 19 de septiembre de 2015].

Mouffe, Chantal (1999) El retorno de lo político. Comunidad, ciudadanía, pluralismo, democracia radical. Barcelona: Paidós.

Mouffe, Chantal (2003) La paradoja democrática. Barcelona: Paidós.

O’Donnell, Guillermo (1997) Contrapuntos. Ensayos escogidos sobre autoritarismo y democratización. Buenos Aires: Paidós.

O’Donnell, Guillermo (1998) “Accountability horizontal”. Ágora, núm. 8, 5-34.

OCMAL, Observatorio de Conflictos Mineros de América Latina (2011) Cuando tiemblan los derechos: extractivismo y criminalización en América Latina. [Disponible en URL: $<$ http://www.conflictosmineros.net/agregar-documento/publicaciones-ocmal/cuando- 
tiemblan-los-derechos-extractivismo-y-criminalizacion-en-america-latina/detail> . Consultado el 28 de enero de 2014].

OCMAL, Observatorio de Conflictos Mineros de América Latina (2012) Legislación minera en el Derecho comparado. Los casos de: Chile, Ecuador, Perú, Guatemala, El Salvador. [Disponible en URL: <http://www.conflictosmineros.net/agregardocumento/publicaciones-ocmal/derechocomparadoocmal/detail $>$. Consultado el 26 de mayo de 2016].

OCMAL, Observatorio de Conflictos Mineros de América Latina (2015) Conflictos mineros en América Latina: extracción, saqueo y agresión. Estado de situación en 2014. [Disponible en URL: <http://www.cpalsocial.org/documentos/185.pdf>. Consultado el 15 de mayo de 2015].

OXFAM (2015) Privilegios que niegan derechos. Desigualdad extrema y secuestro de la democracia en América Latina y el Caribe. [Disponible en URL: $<$ https://www.oxfam.org/sites/www.oxfam.org/files/file_attachments/cr-privilegesdeny-rights-inequality-lac-300915-summ-es.pdf $>$. Consultado el 11 de junio de 2016].

Pérez de la Fuente, Oscar (2012) "Qué democracia(s)". Co-herencia (Medellín, Colombia), vol. 9, núm. 16, 53-79.

Porto Gonçalves, Carlos Walter (2001) Geo-grafías, movimientos sociales, nuevas territoralidades y sustentabilidad. México: Siglo XXI.

Quijano, Aníbal (2007) “Colonialidad del poder y clasificación social”, en S. Castro Gómez y R. Grosfoguel (eds.) El giro decolonial: reflexiones para una diversidad epistémica más allá del capitalismo global. Bogotá: Universidad Javeriana, 93-126.

Rancière, Jacques (2007a) El odio a la democracia. Buenos Aires: Amorrortu.

Rancière, Jacques (2007b) El desacuerdo. Política y filosofía. Argentina: Nueva Visión.

Rawls, John (2003) Liberalismo político. México: Fondo de Cultura Económica.

Reano, Ariana (2009) "Reconsideraciones sobre la paradoja democrática". Andamios Revista de Investigación Social (México, Universidad Autónoma de la Ciudad de México), vol. 5, núm. 10, 309-333.

Rist, Gilbert (2004) The History of Development from Western origins to global faith. New York: Zed Books.

Rosanvallon, Pierre (2007) La Contrademocracia: la política en la era de la desconfianza. Buenos Aires: Editorial Manantial.

RRI, La Iniciativa para los Derechos y los Recursos (2013) Impacto de las industrias extractivas en los derechos colectivos sobre territorios y bosques de los pueblos y comunidades (Bogotá). Disponible en URL: $<$ http://www.rightsandresources.org/documents/files/doc_5914.pdf $>$. Consultado el 3 de febrero de 2015].

Sachs, Wolfgang (1999) “The Archaeology of the Development Idea", en Planet Dialectics: Explorations in Environment \& Development. London: Zed Books, 1-25.

Sack, Robert (1986) Human Territoriality: Its Theory and History. Cambridge: Cambridge University Press.

Sánchez-Albavera, Fernando \& Lardé, Jeannette (2006) Minería y competitividad internacional en América Latina. Santiago de Chile: CEPAL. [Disponible en URL: $<$ http://repositorio.cepal.org/bitstream/handle/11362/6304/S0600325_es.pdf;jsessionid= 698BB20833E8C0ED6ACFA8DEFC942DD2? sequence=1>. Consultado el 8 de septiembre de 2015].

Sandel, Michael (2000) Liberalismo y los límites de la justicia. Barcelona: Gedisa. 
Sanín Restrepo, Ricardo (2014) Teoría crítica constitucional. La democracia a la enésima potencia. Valencia: Tirant lo Blanch.

Sariego, Juan Luis; Reygadas, Luis; Gómez, Miguel Ángel \& Farrera, Javier (1988) El Estado y la minería Mexicana: política, trabajo y sociedad durante el siglo XX. México: Fondo de Cultura Económica.

Saúl, Lilia (2015) "Minas en México". El Universal. [Disponible en URL: $<$ http://archivo.eluniversal.com.mx/graficos/graficosanimados14/EU_Mineria_Mexico/

$>$. Consultado el 5 de mayo de 2015].

Schlosberg, David (2007) Defining Environmental Justice: Theories, Movements, and Nature. Nueva York: Oxford University Press.

Svampa, Maristella (2008) "La disputa por el desarrollo: territorio, movimientos de carácter socio-ambiental y discursos dominantes". [Disponible en URL: $<$ http://www.extractivismo.com/documentos/SvampaSobreDesarrollo.pdf $>$. Consultado el 5 de junio de 2016].

Svampa, Maristella (2012) "Consenso de los commodities, giro ecoterritorial y pensamiento crítico en América Latina”. OSAL (Buenos Aires, CLACSO), vol. XIII, núm. 32, 15-38.

Tarrow, Sidney (2004) El poder en movimiento. Los movimientos sociales, la acción colectiva y la política. Madrid: Alianza.

Urkidi, Leire \& Walter, Mariana (2011) "Dimensions of Environmental Justice in anti-gold mining movements in Latin-America". Geoforum, vol. 42, núm. 6, 683-695.

Villafuerte Solís, Daniel (2014) "Neoextractivismo, megaproyectos y conflictividad en Guatemala y Nicaragua”. Espiral (México, Universidad de Guadalajara), vol. XXI, núm. 61, 109-141.

Villegas, Pablo (2014) “Amistades peligrosas: notas sobre movimientos sociales y gobiernos progresistas", en M. Gandarillas Gonzáles (ed.) Extractivismo: nuevos contextos de dominación y resistencia. Bolivia: CEDIB, 9-66.

Wall, Illan (2012) Human Rights and Constituent Power, without Model or Warranty. London: Routledge.

Walter, Mariana \& Urkidi, Leire (2015) “Consultas comunitarias. Respuestas a la minería a gran escala en América Latina”, en F. de Castro, B. Hogenboom y M. Baud (coords.) Gobernanza ambiental en América Latina. Buenos Aires: CLACSO, ENGOV, 331-370.

West, James \& Schandl, Heinz (2013) "Material use and material efficiency in Latin America and the Caribbean”. Ecological Economics, vol. 94, núm. C, 19-27. [Disponible en URL: $<$ https://research-

repository.griffith.edu.au/bitstream/handle/10072/53316/87884_1.pdf\%3Bsequence=1>. Consultado el 1 de noviembre de 2017].

Yabkowski, Nuria (2013) "El paradigm posfundacional interpelado: Política, democracia e institucionalización para pensar Suramérica hoy". Revista de Filosofía y Teoría Política, núm. $44 . \quad$ [Disponible en URL: <http://www.rfytp.fahce.unlp.edu.ar/article/view/RFyTPn44a04>. Consultado el 19 de febrero de 2015].

Zovatto, Daniel (2001) "La reforma político-electoral en América Latina: evolución, situación actual y tendencias. 1978-2000”. Revista del CLAD, núm. 21, 143-188. 